\title{
Role of plasma adiponectin /C-reactive protein ratio in obesity and type 2 diabetes among African Americans.
}

Preetha Anna Abraham, Selasi Attipoe, Josh B. Kazman, Stacey Anne Zeno, Merrily Poth, Patricia Anne Deuster

Department of Military and Emergency Medicine (MEM) Uniformed Services University of Health Sciences (USUHS) 4301 Jones Bridge Rd, Bethesda, MD 20814 (PA, SA, JK, SZ, PD)

Affiliated Institution(s)

Department of Pediatrics, USUHS (MP)

\begin{abstract}
Background: Obesity is a modifiable risk factor for hypertension and T2D.

Objective(s): We examined relations between fasting plasma adiponectin (ADIP), C-reactive protein (CRP) concentrations and markers of T2D in African Americans (AA).

Methods: Fasting plasma ADIP, CRP, Insulin (IN), HOMA-IR, lipid profiles, body fat percent (\%BF), waist circumference (WC), body mass index (BMI) and blood pressure measures were determined in AA women (W: $n=77)$ and men (M: $n=34)$. Participants were classified into: 1) Normal fasting glucose (FG) and Normal \%BF; 2) Normal FG and High \%BF; and 3) High FG. Results: Compared to men, women had significantly higher mean ADIP (W: $31.4 \pm 2.9$ vs. M: $18.0 \pm 4.4$ ng/L), CRP (W: $3.2 \pm 0.3$ vs. M: $2.0 \pm 0.5 \mathrm{mg} / \mathrm{L}$ ), \%BF (W: $41.2 \pm 0.9$ vs. M: $27.2 \pm 1.3$ ), and BMI (W: $32.3 \pm 0.7$ vs. M: $29.2 \pm 1.1 \mathrm{~kg} / \mathrm{m} 2$ ). Women with normal FG and \%BF had significantly higher ADIP (64.0 \pm 6.0$)$ and lower CRP $(1.3 \pm 0.6)$ concentrations than normal FG/ high \%BF (ADIP: $37.0 \pm 5.0$ and CRP: $3.1 \pm 0.5$ ) and high FG (ADIP: $15.1 \pm 4.1$ and CRP: $4.0 \pm 0.5$ ) groups. Women with high ADIP to CRP ratio had favorable metabolic and anthropometric profiles.

Conclusion: Low ADIP and high CRP are associated with excessive \%BF and FG in AA women. ADIP/CRP, may be useful for detecting metabolic dysregulation.
\end{abstract}

Keywords: Obesity, type 2 diabetes, inflammation.

DOI: https://dx.doi.org/10.4314/ahs.v17i1.13

Cite as: Abraham PA, Attipoe S, Karman JB, Zeno SA, Poth M, Deuster PA. Role of plasma adiponectin / C-reactive protein ratio in obesity and type 2 diabetes among African Americans. Afri Health Sci. 2017;17(1):99-107. bttps:/ /dx.doi.org/10.4314/ ahs.v17i1.13

\section{Introduction}

Obesity, defined as an accumulation of excess body fat ${ }^{1,2}$, increases the risk of developing insulin resistance (IR) and type 2 diabetes (T2D) ${ }^{3}$. Since these conditions reflect metabolic dysregulation and likely systemic inflammation, interest in various bio-active proteins has emerged. Two proteins of interest are adiponectin and $\mathrm{C}$ reactive protein (CRP), produced by adipose tissue and the liver,
Corresponding author:
Preetha Anna Abraham,
Dept. of MEM, USUHS
Building 53, Room 26
4301 Jones Bridge Rd.
Bethesda, MD 20814
Phone: (301) 295-9047
Email: preetha.abraham.ctr@usuhs.edu

respectively ${ }^{4}$. The significant inverse correlation between anti-inflammatory adiponectin and pro-inflammatory CRP reported in certain obese, diabetic and coronary artery disease (CAD) populations ${ }^{5}$, underscores the importance of investigating adiponectin and CRP together to elucidate their opposing relationships in obesity and T2D.

Adipose tissue has traditionally been seen as a storage place for fatty acids; however this notion has been replaced over the last years and adipose tissue has been recognized to play a central role in lipid and glucose metabolism and production of various hormones and cytokines ${ }^{6}$. Adipose tissue is an active endocrine organ that secretes adipocytokines, such as adiponectin. Adiponectin has anti-diabetic and anti-inflammatory properties ${ }^{7}$ and appears to be higher in women than men $^{8-10}$. Discovered in the mid-1990s by four different research groups, it is also referred to as Acrp30, AdipoQ, ApM1, and GBP28 ${ }^{11}$. Within the general population, high adiponectin levels 
have been associated with positive cardiovascular benefits; whereas low values of adiponectin have been linked to a variety of health risks - obesity, metabolic syndrome (MS), IR, T2D and unfavorable lipid profiles ${ }^{12-15}$. Other studies have reported that individuals with CAD and/or T2D have lower plasma adiponectin levels than age- and body mass index- (BMI) matched, non-diabetic individuals without $\mathrm{CAD}^{16}$. Little is known about the regulation of adiponectin, especially in African Americans (AA) and most of the factors and mechanisms affecting adiponectin levels are poorly described ${ }^{17}$.

CRP is another important systemic marker for inflammation and high CRP levels have also been linked to multiple health risks - obesity, T2D, cardiovascular disease (CVD), and hyperlipidemia ${ }^{18-20}$. Due to the apparent strong associations between CRP and health risks, the American Heart Association and Centers for Disease Control and Prevention evaluated CRP as a risk assessment tool and proposed cut points of $<1 \mathrm{mg} / \mathrm{L}, 1-3 \mathrm{mg} / \mathrm{L}$ and $>3 \mathrm{mg} / \mathrm{L}$ be used to identify those at low, average, and high relative risk, respectively for $\mathrm{CVD}^{21}$. Plasma CRP correlates positively with body fat mass, visceral adipose tissue accumulation and plasma insulin ${ }^{22}$, and is associated with $\mathrm{T}_{2} \mathrm{D}^{23}$. Conflicting results have been found with regard to gender differences in CRP. Whereas some studies have reported higher CRP levels in women ${ }^{24,25}$, others have found no gender differences ${ }^{26}$. Ethnic differences in CRP concentrations have also been noted: two large cohort studies found that CRP tends to be higher in AA and Hispanic women than Caucasians and Asian women ${ }^{27,28}$.

However, some obese individuals are free from obesity-related metabolic complications ${ }^{29}$. The aim of this study was to evaluate associated patterns of plasma adiponectin and high sensitivity CRP (hs-CRP) concentrations as a function of metabolic risk factors - fasting blood glucose (FG), insulin (IN), waist circumference (WC), percent body fat $(\% \mathrm{BF})$, mean arterial blood pressure (MAP) and plasma lipids (high density lipoprotein cholesterol/ HDL-C and triglycerides/TG). We hypothesized that, among individuals with increased FG and \%BF, combining adiponectin and CRP would provide a valuable index of obesity related inflammatory and metabolic markers. Therefore, we examined mean differences in metabolic characteristics based on the combined measurements of adiponectin and CRP in AA men and women after classifying participants into three metabolic risk groups: (a) normal FG and \%BF; (b) normal FG and high \%BF; and (c) high FG. In addition we determined whether the plasma adiponectin to CRP ratio level would be a predictive measure of metabolic risk.

\section{Methods \\ Study population}

Participants with complete dataset included 111 AA men $(n=34)$ and women $(n=77)$ between 18 to 60 years of age who were recruited between January 2008 and September 2009 through public advertisements and announcements at local churches in the Greater Washington DC area. Participants who were pregnant or taking steroid medications were excluded for distinct hormonal profiles associated with circulating levels of adiponectin. The study was approved by the Institutional Review Board of the Uniformed Services University of the Health Sciences (USUHS), and written informed consent was obtained from all participants.

\section{Procedures}

Participants visited the laboratory between 0700 and 0900 AM, wherein after obtaining informed consent, blood pressure (BP) and anthropometric evaluations were obtained. Baseline blood collections were obtained after an overnight fast for determination of glucose, insulin, HDL-C, TG, hs-CRP and adiponectin.

\section{Anthropometric measurements}

Body weight was measured with a calibrated balance beam metric scale to the nearest $0.1 \mathrm{~kg}$ and height was measured with a stadiometer to the nearest $0.1 \mathrm{~cm}$. BMI was calculated from height and weight $(\mathrm{kg} / \mathrm{m} 2) . \% \mathrm{BF}$ was estimated by using bioelectric impedance and calculated with the NHANES III prediction formula. WC was measured at the midpoint between the lower rib margin and the iliac crest by using a non-elastic measuring tape. Baseline BP was recorded with a standard BP monitor: measurements were obtained on at least two occasions with the participant in a seated position to ensure accurate assessment. Mean arterial pressure (MAP) was calculated using the formula $((2 *$ Diastolic BP $)+($ Systolic BP $)) / 3^{30}$.

\section{Physiological and biochemical measurements}

Fasting blood glucose concentration was measured with One Touch Ultra monitoring system, hs-CRP analyses were carried out with an Immulite 2000 analyzer (Siemens Medical Solutions Diagnostics, Erlanger, Germany), Insu- 
lin was detected using the Human Insulin ELISA kit from Millipore (St.Charles, Missouri, USA), Adiponectin was detected using the Human Adiponectin sandwich immunoassay kit from Meso Scale Discovery (Gaithersburg, MD, USA) and lipid profiles (Total Cholesterol, HDL-C, LDL-C and TG) were determined in the Clinical Laboratory at the National Institutes of Health Department of Laboratory Medicine using an LX-20 analyzer (Beckman, San Diego, CA). Mean values are expressed in $\mathrm{mm} / \mathrm{L}$, $\mu \mathrm{U} / \mathrm{mL}, \mathrm{mg} / \mathrm{L}, \mathrm{ng} / \mathrm{mL}$ and $\mathrm{mmol} / \mathrm{L}$ respectively. Insulin Resistance was defined by using homeostasis model asessment method of insulin resistance (HOMA-IR) (glucose [in millimoles per liter] $\mathrm{x}$ insulin [in microunits per milliliter]/22.5).

\section{Statistical analysis}

The frequency and distributions of variables were examined to determine normality of distribution and identify outliers. Distributions of plasma adiponectin and CRP levels were skewed, so natural log transformed values were used to normalize the variables for analyses. Men and women with a $\% \mathrm{BF} \geq 25.1$ and 35.1 respectively, were categorized as high $\% \mathrm{BF}$ and participants with FG $\geq 6.1 \mathrm{mmL}$ were considered as diabetic. Three groups were then formed based on FG and \%BF: 1) low risk normal FG and \%BF; 2) moderate risk - normal FG and high \%BF; and 3) high risk - high FG. Covariates, such as age and income, were controlled for in all analyses.

In addition, the ratio of adiponectin (values were multi- plied by 1,000 to generate whole numbers greater than $0.1)$ to CRP was calculated $(\mathrm{mg} / \mathrm{L})$. Cut points were made for 2 groups and participants in the lower point of adiponectin to CRP ratio were classified as "high risk", participants in the upper point were classified as "low risk". Multivariate analyses of variance (MANOVA) were used to determine differences in (1) metabolic (FG, IN, HOMA-IR), lipid profiles (TC, TG, LDL-C and HDL-C) and physical variables (BMI, \%BF, WC, MAP) as a function of metabolic grouping low and high adiponectin to CRP ratio and (2) variations in plasma adiponectin, CRP and adiponectin to CRP ratio in the three $\% \mathrm{BF}$ and diabetes status groups. Partial correlations were calculated to find associations between adiponectin and CRP with physical, lipid and metabolic measurements.

The sample size of 111 (69\% female) was adequate to detect moderate group differences across two independent groups of different sizes $(\mathrm{d}=0.6)$, and across three sized groups $(\mathrm{f}=0.30)$. Participants with complete data were included in the present analysis. Results are expressed as mean \pm SEM and the statistical significance was set at $\mathrm{p} \leq$ 0.05. Statistical analyses were performed with IBM SPSS 20.0 for Windows (SPSS Inc., Chicago, Ill., USA).

\section{Results}

Compared to men, women had higher plasma hs-CRP (Women: $3.2 \pm 0.3 \mathrm{mg} / \mathrm{L}$, Men: $2.0 \pm 0.5 \mathrm{mg} / \mathrm{L} ; \mathrm{p} \leq$ 0.05 ), adiponectin (Women: $31.4 \pm 2.9 \mathrm{ng} / \mathrm{mL}$, Men: 18.0 $\pm 4.4 \mathrm{ng} / \mathrm{mL} ; \mathrm{p} \leq 0.05), \% \mathrm{BF}$ (Women: $41.2 \pm 0.9$, Men: $27.2 \pm 1.3 ; \mathrm{p} \leq 0.001$ ) and BMI (Women: $32.3 \pm 0.7$,

Table 1: Metabolic and physical characteristics by gender (Mean \pm S.E.M)

\begin{tabular}{c|c|c}
\hline Variables & Women $(\mathrm{n}=77)$ & Men $(\mathrm{n}=34)$ \\
\hline CRP $(\mathrm{mg} / \mathrm{L})^{*}$ & $3.2 \pm 0.3$ & $2.0 \pm 0.5$ \\
Adiponectin $(\mathrm{ng} / \mathrm{mL})^{* *}$ & $31.4 \pm 2.9$ & $18.0 \pm 4.4$ \\
1'Adiponectin/CRP ratio & $43.2 \pm 7.5$ & $28.0 \pm 11.3$ \\
Total Cholesterol (mmol/L) & $4.1 \pm 0.1$ & $4.0 \pm 0.1$ \\
Triglycerides (mmol/L) & $1.0 \pm 0.1$ & $1.2 \pm 0.1$ \\
LDL-C (mmol/L) & $2.4 \pm 0.1$ & $2.3 \pm 0.1$ \\
HDL-C (mmol/L) & $1.3 \pm 0.04$ & $1.2 \pm 0.06$ \\
Fasting Glucose (mmol/L) & $6.2 \pm 0.2$ & $6.3 \pm 0.2$ \\
Insulin $(\mu \mathrm{U} / \mathrm{mL})$ & $7.5 \pm 0.9$ & $7.4 \pm 1.3$ \\
HOMA-IR & $2.2 \pm 0.3$ & $2.2 \pm 0.4$ \\
Waist Circumference $(\mathrm{cm})$ & $99.0 \pm 2.0$ & $98.5 \pm 3.0$ \\
Percent Body Fat*** & $41.2 \pm 0.9$ & $27.2 \pm 1.3$ \\
Body Mass Index $\left(\mathrm{kg} / \mathrm{m}^{2}\right)^{*}$ & $32.3 \pm 0.7$ & $29.2 \pm 1.1$ \\
MAP $(\mathrm{mm} \mathrm{Hg})$ & $99.0 \pm 2.0$ & $101.0 \pm 2.3$ \\
\hline
\end{tabular}

Note: Mean Differences significant at $* \mathrm{p} \leq 0.05, * * \mathrm{p} \leq 0.01, * * * \mathrm{p} \leq 0.001$ (controlled for age and income; ${ }^{1}$ ratio of adiponectin (values multiplied by 1000 to generate whole numbers) to CRP.

Abbreviations: C reactive protein (CRP); Low-Density Lipoprotein Cholesterol (LDL-C); High-Density Lipoprotein Cholesterol (HDL-C); Homeostasis Model Assessment Method of Insulin Resistance (HOMA-IR); Mean Arterial

Pressure (MAP). 
Men: $29.2 \pm 1.1 ; \mathrm{p} \leq 0.05)$, as shown in Table 1 .

Table 2 presents correlation coefficients for plasma adiponectin and CRP with physical (BMI, WC, MAP and $\% \mathrm{BF}$ ), metabolic and lipid (FG, IN, HOMA-IR, TC, TG, LDL-C and HDL-C) variables. A significant negative correlation was observed between plasma adiponectin and $\mathrm{CRP}$ in AA men $(\mathrm{r}=-0.39, \mathrm{p} \leq 0.05)$ and women $(\mathrm{r}=$
$-0.32, \mathrm{p} \leq 0.01)$. Adiponectin was significantly and negatively associated with BMI and WC in both men and women, whereas in women only, adiponectin was also associated with \%BF, IN, FG and HOMA-IR. In men, there was a significant negative association between CRP and HDL-C; a positive association between CRP and $\mathrm{BMI}$ in both men and women and with WC, \%BF, FG,

Table 2: Partial correlations between adiponectin, CRP, physical and metabolic variables by gender (Women: $n=77 ;$ Men: $n=34$ )

\begin{tabular}{|c|c|c|c|c|}
\hline \multirow[t]{2}{*}{ Variables } & \multicolumn{2}{|c|}{ Adiponectin } & \multicolumn{2}{|c|}{ CRP } \\
\hline & Women & Men & Women & Men \\
\hline Adiponectin (mg/L) & - & - & $-0.32 * *$ & $-0.34 *$ \\
\hline $\mathrm{CRP}(\mathrm{mg} / \mathrm{L})$ & $-0.32 * *$ & $-0.39 *$ & - & - \\
\hline BMI $\left(\mathrm{kg} / \mathrm{m}^{2}\right)$ & $-0.23 *$ & $-0.40 *$ & $0.51 * * *$ & $0.45 * *$ \\
\hline $\mathrm{WC}(\mathrm{cm})$ & $-0.30 * *$ & $-0.34 *$ & $0.57 * * *$ & 0.32 \\
\hline MAP (mm Hg) & 0.13 & -0.13 & 0.16 & 0.002 \\
\hline Body Fat $(\%)$ & $-0.24 *$ & -0.26 & $0.50 * * *$ & 0.33 \\
\hline FG $(\mathrm{mmol} / \mathrm{L})$ & $-0.34 * *$ & -0.05 & $0.30 * *$ & -0.10 \\
\hline $\mathrm{IN}(\mu \mathrm{U} / \mathrm{mL})$ & $-0.33 * *$ & -0.11 & $0.30 *$ & 0.17 \\
\hline HOMA-IR & $-0.33 * *$ & -0.12 & $0.30 * *$ & 0.15 \\
\hline $\mathrm{TC}(\mathrm{mmol} / \mathrm{L})$ & -0.10 & -0.15 & 0.12 & 0.04 \\
\hline TG (mmol/L) & -0.22 & -0.23 & 0.16 & 0.13 \\
\hline LDL-C (mmol/L) & -0.13 & -0.15 & 0.16 & 0.17 \\
\hline HDL-C (mmol/L) & 0.16 & 0.17 & -0.11 & $-0.36^{*}$ \\
\hline
\end{tabular}

\begin{abstract}
Note: Significance of correlation coefficients shown at ${ }^{*} \mathrm{p} \leq 0.05, * * \mathrm{p} \leq 0.01, * * * \mathrm{p} \leq 0.001$ (controlled for age and income).

Abbreviations: C reactive protein (CRP); Body Mass Index (BMI); Waist Circumference (WC);

Mean Arterial Pressure (MAP); Fasting Glucose (FG); Insulin (IN); Homeostasis Model

Assessment of Insulin Resistance (HOMA-IR); Total Cholesterol (TC); Triglycerides (TG);

Low-Density Lipoprotein Cholesterol (LDL-C); High-Density Lipoprotein Cholesterol (HDL-

C).
\end{abstract}

IN and HOMA-IR, in women only.

Table 3 shows metabolic and physical baseline differences based on low and high adiponectin to CRP ratio. AA women with a high adiponectin to CRP ratio had significantly lower FG, IN, HOMA-IR, WC, \%BF and BMI while for men, only HDL-C, BMI and \%BF were signifi-

Table 3: Metabolic and physical characteristic based on low and high a diponectin to CRP ratio (Mean \pm S.E.M)

\begin{tabular}{c|cc|cc|}
\hline Variables & \multicolumn{2}{|c|}{$\begin{array}{c}\text { Adiponectin/CRP ratio } \\
\text { WOMEN }\end{array}$} & \multicolumn{2}{c|}{$\begin{array}{c}\text { Adiponectin/CRP ratio } \\
\text { MEN }\end{array}$} \\
& Low $(\mathbf{n}=\mathbf{3 9})$ & High (n=38) & Low (n=17) & High (n=17) \\
\hline TC (mmol/L) & $4.2 \pm 0.1$ & $4.0 \pm 0.1$ & $4.1 \pm 0.2$ & $2.1 \pm 0.2$ \\
LDL-C (mmol/L) & $2.4 \pm 0.1$ & $2.3 \pm 0.1$ & $2.4 \pm 0.1$ & $1.0 \pm 0.1$ \\
TG (mmol/L) & $1.1 \pm 0.1$ & $1.0 \pm 0.1$ & $1.4 \pm 0.1$ & $1.3 \pm 0.1$ \\
HDL-C (mmol/L) & $1.3 \pm 0.1$ & $1.3 \pm 0.1$ & $1.1 \pm 0.1 *$ & $6.2 \pm 0.5$ \\
FG (mmol/L) & $6.4 \pm 0.1 * *$ & $6.0 \pm 0.2$ & $7.0 \pm 0.5$ & $1.4 \pm 0.7$ \\
IN ( $\mu$ U/mL) & $10.0 \pm 1.0 * *$ & $5.0 \pm 1.0$ & & $94.1 \pm 4.0$ \\
HOMA-IR & $3.0 \pm 0.3 * *$ & $1.4 \pm 0.3$ & $3.0 \pm 0.7$ & $25.2 \pm 1.3$ \\
WC (cm) & $104.1 \pm 2.6 * *$ & $92.1 \pm 3.0$ & $104.1 \pm 3.7$ & $27.3 \pm 1.1$ \\
BF (\%) & $44.0 \pm 1.2 * *$ & $39.0 \pm 1.3$ & $30.0 \pm 1.3 *$ & $102 \pm 3.3$
\end{tabular}

Note: Mean Differences significant at $* \mathrm{p} \leq 0.05, * * \mathrm{p} \leq 0.01, * * * \mathrm{p} \leq 0.001$; (controlled for age and income; participants who were in the lower 50 percentile of adiponectin to CRP ratio were classified as "low", participants in the upper 50 percentile were classified as "high").

Abbreviations: Total Cholesterol (TC); Low-Density Lipoprotein Cholesterol (LDL-C); Triglycerides (TG); High-Density Lipoprotein Cholesterol (HDL-C); Fasting Glucose (FG); Insulin (IN); Homeostasis Model Assessment of Insulin Resistance (HOMA- IR); Waist Circumference (WC); Body Mass Index (BMI); Mean Arterial Pressure (MAP). 
cantly different between the two ratio groups.

Figure 1 presents mean plasma adiponectin, CRP and adiponectin to CRP ratio by the three metabolic groupings and gender. Women with normal FG/\%BF had significantly higher adiponectin $(64 \pm 6.0 \mathrm{ng} / \mathrm{mL})$ and lower
CRP $(1.3 \pm 0.6 \mathrm{mg} / \mathrm{L})$ concentrations than women with normal FG and high \%BF (adiponectin: $37.0 \pm 5.0 \mathrm{ng} /$ $\mathrm{mL}$ and CRP: $3.1 \pm 0.5 \mathrm{mg} / \mathrm{L}$ ) and high FG (adiponectin: $15.1 \pm 4.1 \mathrm{ng} / \mathrm{mL}$ and CRP: $4.0 \pm 0.5 \mathrm{mg} / \mathrm{mL}$ ). Additionally, adiponectin to CRP ratio differed significantly in all three groups among women. This pattern did not hold in
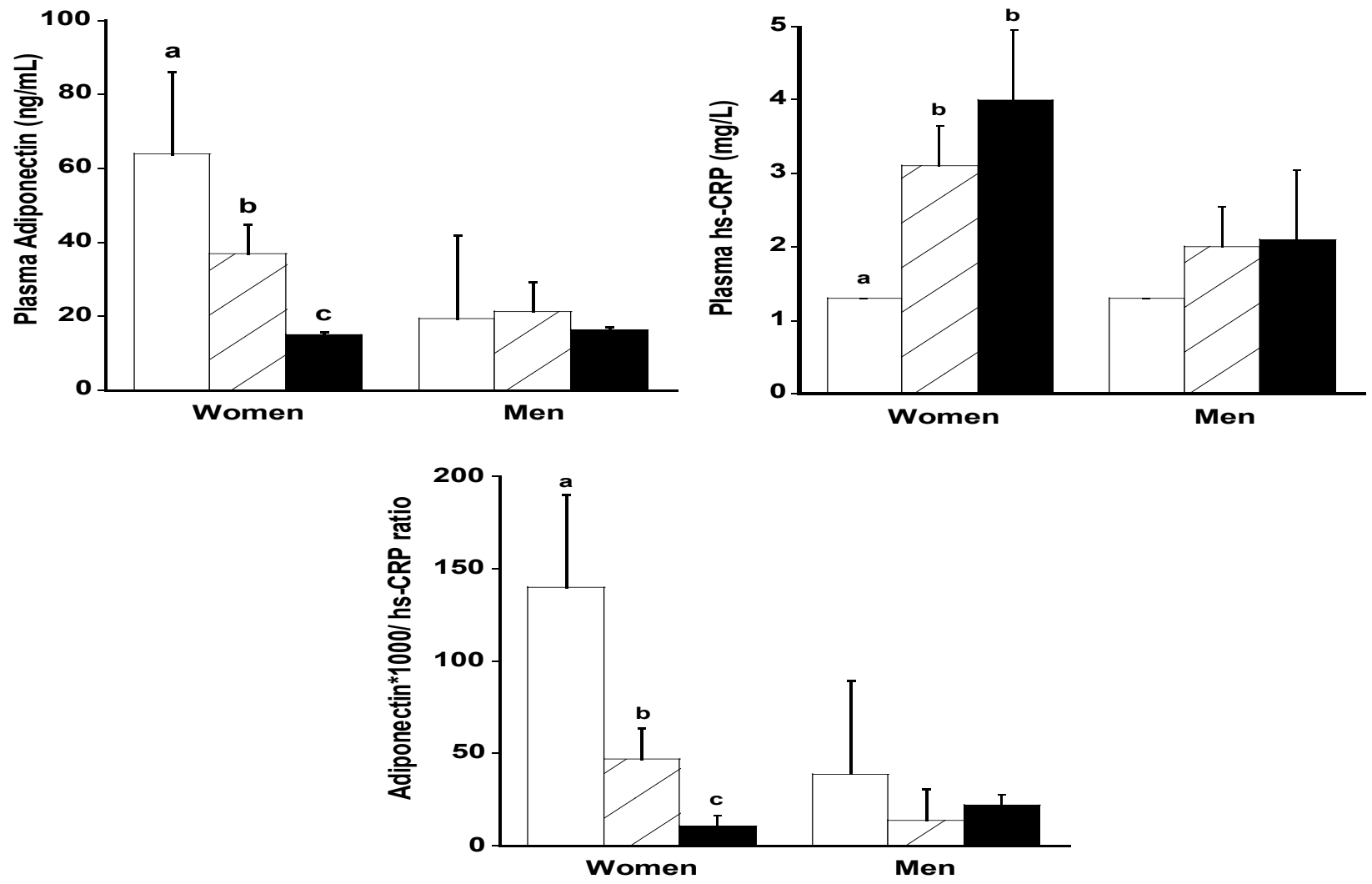

Figure 1: Plasma adiponectin, CRP, and the adiponectin to CRP ratio based on normal \%body fat and fasting glucose $($ Women = 23; Men = 16), high \%body fat and normal fasting glucose $($ Women = 30; Men = 12) and normal/high \% body fat/high fasting glucose $($ Women $=43 ;$ Men $=21)($ Mean \pm S.E.M)

Note: Means with different superscript letters differ significantly; $\mathrm{p} \leq 0.05$ (controlled for age and income; ratio of adiponectin to CRP values were multiplied by 1000 to generate whole numbers). Abbreviations: CRP: C-Reactive Protein).

AA men.

\section{Discussion}

Excessive body fat is a major risk for cardiovascular disease and increases the risk of hypertension, dyslipidemia, hyperglycemia and low-grade inflammation process. Two proteins that are associated with T2D and obesity are adiponectin and CRP. Adiponectin is exclusively produced by adipocytes, circulates in plasma, and is reduced in obesity, IR, MS and T2D. Adiponectin helps to regulate the release of various inflammatory and anti-inflammatory cytokines $^{13,31}$. Whereas CRP released from the liver in re- sponse to the inflammatory cytokines - IL-1 beta, IL-6 and TNF-alpha is a risk factor for cardiovascular events and is related to an increased risk of incident T2D. Although CRP and adiponectin were negatively related, results from the present study strongly suggests that AA women with low adiponectin and high CRP are likely to have excessive body fat and glucose dysregulation as compared to AA women with high adiponectin and low CRP values. In contrast, women who are obese, but not pre-diabetic, are likely to have moderately high adiponectin and CRP values. A predictive cut-off for adiponectin could be developed, but an adiponectin/CRP ratio may 
preclude the need for such a cut-off.

Previous studies have shown that circulating CRP is a predictor of $\mathrm{CVD}^{32}$ whereas adiponectin levels are reflective of IR, central obesity and intra-abdominal fat accumulation $^{16,33,34}$. In the present study, adiponectin was negatively correlated with many markers (BMI, WC, \%BF, and FG), whereas CRP was positively correlated with various metabolic markers (BMI, WC, \%BF, IN, FG and HOMA-IR) in AA women. Although CRP and adiponectin were negatively related, the strength of the relationship was low; combining the two variables may provide more valuable information regarding obesity and diabetes than any of the individual variables. Interestingly, the observed trends were not seen in AA men.

Adiponectin and CRP are independent risk factors of CVD, together serve a synergistic role in metabolic regulation in the general population and T2D subjects ${ }^{35-37}$. We found that AA women with high adiponectin and low CRP levels, which translated into a high ratio, had significantly lower FG, IN, HOMA-IR, WC, \%BF and BMI relative to those with a low ratio. A combined measurement of these markers may be more useful for detecting persons at high risk for cardiovascular disease and diabetes, than one of the measure alone.

Although obesity is a risk factor for insulin resistance, CVD and T2DM, not every obese individual suffers the same metabolic dysregulation. In the 1980s, a subgroup of metabolically normal, but obese, individuals with relatively high insulin sensitivity and a favorable metabolic profile was reported by several investigators ${ }^{38}$. A unique subset of obese individuals appears to be protected from developing the metabolic disturbances typically associated with obesity. These individuals, despite being obese display normal to high insulin sensitivity and favorable cardiovascular risk profiles ${ }^{39-43}$. Thus, it is important to characterize differences between these groups to uncover additional mechanisms connecting obesity and health risk. In our study, we examined differences in adiponectin and CRP and the adiponectin to CRP ratio in AA men and women with normal $\% \mathrm{BF} / \mathrm{FG}$, high $\% \mathrm{BF} /$ normal FG and normal and high $\% \mathrm{BF}$ with high FG. Whereas no differences were noted between the men by metabolic group assignment, plasma adiponectin was consistently lower and CRP higher in women in the high FG group compared to women in the normal $\% \mathrm{BF} / \mathrm{FG}$ and in the high \% BF/normal FG group. The high FG also had a significantly lower adiponectin to CRP ratio relative to the other metabolic groups of women. Our findings are also consistent with epidemiological studies showing that circulating levels of adiponectin are lower in diabetic than in healthy individuals ${ }^{44,45}$. Additionally, studies have reported that heavier individuals had greater health benefit and lower health risks from high levels of adiponectin than their lean counterparts ${ }^{46,47}$. Whether a combined measure of these two markers, such as adiponectin/CRP ratio, would be useful for detecting and monitoring metabolic and low-grade inflammation health risk in AA women remains to be fully understood.

Gender differences in adiponectin and CRP levels have previously been reported ${ }^{23,48,49}$, and our study provides further evidence of these gender differences because AA women had significantly higher adiponectin and CRP levels than AA men. Additionally, we found a significant negative association between plasma adiponectin and CRP in both genders.

\section{Limitations}

We had data on fewer men than women, and this may have limited our findings among men. The present study examined only AA and it would be interesting to examine differences across other ethnic overweight/obese and diabetic/ non diabetic groups by gender as well. Longitudinal research with more participants will be necessary to determine the independent and interactive relationships between adiponectin and hs-CRP, and the health outcomes they reflect.

\section{Conclusion}

A statistically significant negative association was observed between plasma adiponectin and CRP in both AA men and women; AA women had higher adiponectin and CRP levels compared to AA men. Overall, AA women with high fasting glucose and HOMA -IR had lower concentrations of adiponectin and higher CRP levels than AA women with normal glucose. Measures of obesity and metabolic dysregulation are more strongly related to CRP and adiponectin in AA women than in AA men. Finally, the ratio of circulating levels of adiponectin to CRP was examined and found to discriminate between AA women who were diabetic versus those who were not, regardless of obesity status, which suggests that adiponectin may have a protective effect against obesity related metabolic derangements in AA women. Prospective studies will be 
needed to confirm this finding.

\section{Acknowledgements}

The project was funded by NCMHD, National Institutes of Health, Bethesda, MD, Establishing Exploratory NCMHD Research Centers of Excellence (P20), RFAMD-07-001. We thank Dr. Alan Remaley's team at NIH for their contributions.

\section{Conflict of interest and disclaimer}

The authors have no conflict of interests in the present study. The views expressed are those of the authors and do not reflect the official policy position of the USUHS, Department of the Army, Department of the Navy, Department of Air Force, the United States Department of Defense or the United States Government.

\section{Author contributions}

Preetha Anna Abraham: drafted and wrote the present manuscript, contributed to the conception and design of research, acquisition of data, prepared figures, performed experiments, and conducted statistical analysis; Selasi Attipoe: assisted with performing experiments, acquisition of data, and manuscript preparation; Josh Kazman: assisted with statistical analyses and interpretation of results; Stacey Zeno: supervision of study execution, acquisition of data, and assisted with manuscript preparation; Merrily Poth and Patricia Deuster: acquired funding for the research, supervision of study execution, contributed to the study design, edited and approved the final version of the manuscript.

\section{References}

1. Deurenberg P, Deurenberg-Yap M, Guricci S. Asians are different from Caucasians and from each other in their body mass index/body fat per cent relationship. Obesity reviews : an official journal of the International Association for the Study of Obesity. 2002;3(3):141-6.

2. Kumada M, Kihara S, Sumitsuji S, Kawamoto T, Matsumoto S, Ouchi N, et al. Association of hypoadiponectinemia with coronary artery disease in men. Arteriosclerosis, thrombosis, and vascular biology. 2003;23(1):85-9.

3. Maggio CA, Pi-Sunyer FX. The prevention and treatment of obesity. Application to type 2 diabetes. Diabetes care. 1997;20(11):1744-66.

4. Al-Daghri NM, Al-Attas OS, Al-Rubeaan K, Sallam R. Adipocytokine profile of type 2 diabetics in metabolic syndrome as defined by various criteria. Diabetes/metabo- lism research and reviews. 2008;24(1):52-8.

5. Matsushita K, Yatsuya H, Tamakoshi K, Wada K, Otsuka $\mathrm{R}$, Zhang $\mathrm{H}$, et al. Inverse association between adiponectin and C-reactive protein in substantially healthy Japanese men. Atherosclerosis. 2006;188(1):184-9.

6. Hajer GR, van Haeften TW, Visseren FL. Adipose tissue dysfunction in obesity, diabetes, and vascular diseases. European Heart Journal. 2008;29(24):2959-71.

7. Ouchi N, Kihara S, Funahashi T, Nakamura T, Nishida M, Kumada M, et al. Reciprocal association of C-reactive protein with adiponectin in blood stream and adipose tissue. Circulation. 2003;107(5):671-4.

8. Laughlin GA, Barrett-Connor E, May S. Sex-specific determinants of serum adiponectin in older adults: the role of endogenous sex hormones. Int J Obes (Lond). 2007;31(3):457-65.

9. Tabatabaei-Malazy O, Hasani-Ranjbar S, Amoli MM, Heshmat R, Sajadi M, Derakhshan R, et al. Gender-specific differences in the association of adiponectin gene polymorphisms with body mass index. The review of diabetic studies: RDS. 2010;7(3):241-6.

10. Yarrow JF, Beggs LA, Conover CF, McCoy SC, Beck DT, Borst SE. Influence of androgens on circulating adiponectin in male and female rodents. PloS one. 2012;7(10):e47315.

11. Bush NC, Darnell BE, Oster RA, Goran MI, Gower BA. Adiponectin is lower among African Americans and is independently related to insulin sensitivity in children and adolescents. Diabetes. 2005;54(9):2772-8.

12. Arita Y, Kihara S, Ouchi N, Takahashi M, Maeda K, Miyagawa J, et al. Paradoxical decrease of an adipose-specific protein, adiponectin, in obesity. 1999. Biochemical and biophysical research communications. 2012;425(3):560-4.

13. Chandran M, Phillips SA, Ciaraldi T, Henry RR. Adiponectin: more than just another fat cell hormone? Diabetes care. 2003;26(8):2442-50.

14. Davis SK, Gebreab SY, Xu R, Riestra P, Khan RJ, Sumner AE, et al. Association of adiponectin with type 2 diabetes and hypertension in African American men and women: the Jackson Heart Study. BMC cardiovascular disorders. 2015;15:13.

15. Li S, Shin HJ, Ding EL, van Dam RM. Adiponectin levels and risk of type 2 diabetes: a systematic review and meta-analysis. JAMA: The Journal of the American Medical Association. 2009;302(2):179-88.

16. Goropashnaya AV, Herron J, Sexton M, Havel PJ, Stanhope KL, Plaetke R, et al. Relationships between 
plasma adiponectin and body fat distribution, insulin sensitivity, and plasma lipoproteins in Alaskan Yup'ik Eskimos: the Center for Alaska Native Health Research study. Metabolism: clinical and experimental. 2009;58(1):22-9.

17. Rolland YM, Haren MT, Patrick P, Banks WA, Malmstrom TK, Miller DK, et al. Adiponectin levels in obese and non-obese middle-aged African-American women. Obes Res Clin Pract. 2007;1(1):1-78.

18. Blake GJ, Rifai N, Buring JE, Ridker PM. Blood pressure, C-reactive protein, and risk of future cardiovascular events. Circulation. 2003;108(24):2993-9.

19. Lear SA, Chen MM, Birmingham CL, Frohlich JJ. The relationship between simple anthropometric indices and C-reactive protein: ethnic and gender differences. Metabolism: clinical and experimental. 2003;52(12):1542-6.

20. Visser M, Bouter LM, McQuillan GM, Wener MH, Harris TB. Elevated C-reactive protein levels in overweight and obese adults. JAMA: The Journal of the American Medical Association. 1999;282(22):2131-5.

21. Kelley-Hedgepeth A, Lloyd-Jones DM, Colvin A, Matthews KA, Johnston J, Sowers MR, et al. Ethnic differences in C-reactive protein concentrations. Clin Chem. 2008;54(6):1027-37.

22. Ong KL, Tso AW, Xu A, Law LS, Li M, Wat NM, et al. Evaluation of the combined use of adiponectin and C-reactive protein levels as biomarkers for predicting the deterioration in glycaemia after a median of 5.4 years. $D i$ abetologia. 2011;54(10):2552-60.

23. Ahonen T, Vanhala M, Kautiainen H, Kumpusalo E, Saltevo J. Sex differences in the association of adiponectin and low-grade inflammation with changes in the body mass index from youth to middle age. Gender medicine. 2012;9(1):1-8.

24. Arena R, Arrowood JA, Fei DY, Helm S, Kraft KA. The relationship between $\mathrm{C}$-reactive protein and other cardiovascular risk factors in men and women. $J$ Cardiopulm Rehabil. 2006;26(5):323-7; quiz 8-9.

25. Williams MJ, Milne BJ, Hancox RJ, Poulton R. C-reactive protein and cardiorespiratory fitness in young adults. European journal of cardiovascular prevention and rehabilitation : official journal of the European Society of Cardiology, Working Groups on Epidemiology \& Prevention and Cardiac Rehabilitation and Exercise Physiology. 2005;12(3):216-20.

26. Thorand B, Baumert J, Doring A, Herder C, Kolb H, Rathmann W, et al. Sex differences in the relation of body composition to markers of inflammation. Atherosclerosis.
2006;184(1):216-24.

27. Lakoski SG, Cushman M, Criqui M, Rundek T, Blumenthal RS, D'Agostino RB, Jr., et al. Gender and C-reactive protein: data from the Multiethnic Study of Atherosclerosis (MESA) cohort. American Heart Journal. 2006;152(3):593-8.

28. Matthews KA, Sowers MF, Derby CA, Stein E, Miracle-McMahill H, Crawford SL, et al. Ethnic differences in cardiovascular risk factor burden among middle-aged women: Study of Women's Health Across the Nation (SWAN). American Heart Journal. 2005;149(6):1066-73.

29. Primeau V, Coderre L, Karelis AD, Brochu M, Lavoie ME, Messier V, et al. Characterizing the profile of obese patients who are metabolically healthy. Int J Obes (Lond). 2011;35(7):971-81.

30. Ghazzi MN, Perez JE, Antonucci TK, Driscoll JH, Huang SM, Faja BW, et al. Cardiac and glycemic benefits of troglitazone treatment in NIDDM. The Troglitazone Study Group. Diabetes. 1997;46(3):433-9.

31. Tilg H, Moschen AR. Adipocytokines: mediators linking adipose tissue, inflammation and immunity. Nature reviews Immunology. 2006;6(10):772-83.

32. Liao CH, Li HY, Yu HJ, Chiang HS, Lin MS, Hua CH, et al. Low serum sex hormone-binding globulin: marker of inflammation? Clinica chimica acta; International Journal of clinical chemistry. 2012;413(7-8):803-7.

33. Mohammadzadeh G, Zarghami N. Hypoadiponectinemia in obese subjects with type II diabetes: A close association with central obesity indices. Journal of research in medical sciences: The Official Journal of Isfahan University of Medical Sciences. 2011;16(6):713-23.

34. Salmenniemi U, Ruotsalainen E, Vanttinen M, Vauhkonen I, Pihlajamaki J, Kainulainen S, et al. High amount of visceral fat mass is assoc iated with multiple metabolic changes in offspring of type 2 diabetic patients. Int J Obes (Lond). 2005;29(12):1464-70.

35. Saisho Y, Hirose H, Seino Y, Saito I, Itoh H. Usefulness of C-reactive protein to high-molecular-weight adiponectin ratio to predict insulin resistance and metabolic syndrome in Japanese men. Journal of atherosclerosis and thrombosis. 2010;17(9):944-52.

36. Saisho Y, Hirose H, Yamamoto Y, Nakatani H, Itoh H. Combination of C-reactive protein and high molecular weight (HMW)-adiponectin reflects further metabolic abnormalities compared with each of them alone in Japanese type 2 diabetic subjects. Endocrine Journal. 2008;55(2):331-8. 
37. Al-Hamodi Z, Al-Habori M, Al-Meeri A, Saif-Ali R. Association of adipokines, leptin/adiponectin ratio and C-reactive protein with obesity and type 2 diabetes mellitus. Diabetology \& metabolic syndrome. 2014;6(1):99.

38. Brochu M, Tchernof A, Dionne IJ, Sites CK, Eltabbakh GH, Sims EA, et al. What are the physical characteristics associated with a normal metabolic profile despite a high level of obesity in postmenopausal women? The Journal of clinical endocrinology and metabolism. 2001;86(3):1020-5. 39. Conus F, Allison DB, Rabasa-Lhoret R, St-Onge M, St-Pierre DH, Tremblay-Lebeau A, et al. Metabolic and behavioral characteristics of metabolically obese but normal-weight women. The Journal of clinical endocrinology and metabolism. 2004;89(10):5013-20.

40. Despres JP, Lemieux I. Abdominal obesity and metabolic syndrome. Nature. 2006;444(7121):881-7.

41. Meigs JB, Wilson PW, Fox CS, Vasan RS, Nathan DM, Sullivan LM, et al. Body mass index, metabolic syndrome, and risk of type 2 diabetes or cardiovascular disease. The Journal of clinical endocrinology and metabolism. 2006;91(8):2906-12.

42. Pataky Z, Bobbioni-Harsch E, Golay A. Open questions about metabolically normal obesity. Int J Obes (Lond). 2010;34 Suppl 2:S18-23.

43. Ruderman NB, Schneider SH, Berchtold P. The "metabolically-obese," normal-weight individual. The American Journal of clinical nutrition. 1981;34(8):1617-21.

44. Daimon M, Oizumi T, Saitoh T, Kameda W, Hirata A,
Yamaguchi H, et al. Decreased serum levels of adiponectin are a risk factor for the progression to type 2 diabetes in the Japanese Population: the Funagata study. Diabetes care. 2003;26(7):2015-20.

45. Nayak S, Soon SQ, Kunjal R, Ramadoo R, Baptiste $\mathrm{O}$, Persad J, et al. Relationship between adiponectin, inflammatory markers and obesity in type 2 diabetic and non-diabetic Trinidadians. Archives of physiology and biochemistry. 2009;115(1):28-33.

46. Aguilar-Salinas CA, Garcia EG, Robles L, Riano D, Ruiz-Gomez DG, Garcia-Ulloa AC, et al. High adiponectin concentrations are associated with the metabolically healthy obese phenotype. The Journal of clinical endocrinology and metabolism. 2008;93(10):4075-9.

47. Morrison JA, Glueck CJ, Daniels S, Wang P, Horn P, Stroop D. Paradoxically high adiponectin and the healthy obese phenotype in obese black and white 16-year-old girls. Translational research: The Journal of laboratory and clinical medicine. 2010;156(5):302-8.

48. Bo S, Gentile L, Ciccone G, Baldi C, Benini L, Dusio $\mathrm{F}$, et al. The metabolic syndrome and high C-reactive protein: prevalence and differences by sex in a southern-European population-based cohort. Diabetes/metabolism research and reviews. 2005;21(6):515-24.

49. Matsuda Y, Tanioka T, Yoshioka T, Nagano T, Hiroi T, Yoshikawa $\mathrm{K}$, et al. Gender differences in association of plasma adiponectin with obesity reflect resultant insulin resistance in non-diabetic Japanese patients with schizophrenia. Psychiatry and clinical neurosciences. 2005;59(3):266- 